\title{
Critical Design :: Is It Just Designers Doing Ethnography or Does It Offer Something More for Interaction Design?
}

\author{
Michael Smyth ${ }^{1}$, Chris Speed ${ }^{2}$, and Martin Brynskov ${ }^{3}$ \\ ${ }^{1}$ Centre for Interaction Design, Edinburgh Napier University, UK \\ ${ }^{2}$ Edinburgh College of Art, Edinburgh, UK \\ ${ }^{3}$ Centre for Digital Urban Living, \\ Aarhus University, Denmark \\ m.smyth@napier.ac.uk, c.speed@eca.ac.uk, brynskov@imv.au.dk
}

\begin{abstract}
The panel will discuss the contribution of Critical Design to the field of Interaction Design and reflect on the insights that it provides on interaction.
\end{abstract}

Keywords: Critical Design \& Interaction Design.

\section{Introduction}

This panel will explore whether Critical Design offers new insight as a method for articulating future interactions. Will its promise deliver or are Interaction Designers destined to experience the same feeling of disappointment that HCI practitioners felt after the novelty of Ethnography began to fade? Will the design fictions of Critical Design mature into design facts or will the demand to solve problems short circuit the method? Indeed, is problem solving per se an out-moded way of design thinking in the context of today's multi-layered hybrid society?

\section{The Panel :: Critical Design and Interaction Design}

The panel will comprise of academic practitioners who seek to inform their thinking through practice. Each panellist will describe their research and, in particular, will focus on the value of Critical Design as it pertains to their work. The presentations will set the tone for the panel and will be designed to engage the audience in a discussion about methods through which to better understand interaction. The aim of the panel will be to address questions, such as:

- how do we extend the requirements horizon beyond existing systems in order to identify emerging themes within the field?

- how do we begin to design concepts when we don't know what that design space will look like, let alone who the user population will be?

It is envisaged that the outcome of the panel session will be an increased awareness of the possible contribution of design to the requirements generation process. In particular, how Critical Design can act as a mechanism to ask questions and make us think. 
Requirements generation has a strong tradition within the field of Human Computer Interaction (HCI). Numerous methods have been adopted from a variety of disciplines and these have been tailored to address the specific demands of HCI. Traditional HCI tends to take a rational, engineering focussed approach, that of problem solving, where insufficiently structured problem statements cause difficulties in arriving at appropriate solutions. Part of the resolution of this situation rests on application of methodologies that attempt to refine and clarify the problem statement itself in order to move towards appropriate systems. Interaction Design, as a more recently developed discipline, takes a more 'designerly' approach to this activity by considering both the problem and the solution in a more fluid and intertwined manner, accepting lack of situational certainty and embracing the contextual and evolutionary nature of designed systems in use [1].

The panel will explore how design can shape strategy and set agendas for future generations of technology and design outcomes. The challenge facing such early stage concept generation is to project forward by tapping into higher level needs and desires that are often not obviously apparent. Critical Design [2] presents design as a catalyst or provocation for thought. It is a strategy for exploring the space that lies tantalisingly beyond the current and the now. By contextualising this approach at the edges of our knowledge, it is possible to use design to create 'design fictions' [3]. Examples of fictions will demonstrate their effect of humanising the future and thereby enabling us to focus on the minutiae of behaviour and the subsequent questions that are revealed through the exposure of our needs, desires, habits, rituals, values and priorities. At the core of Critical Design is the attempt to challenge our assumptions and preconceptions about the role that products and services play in everyday life.

In the introduction to the recent book entitled NonObject [4], Barry Katz described design as a means of surveying the bounds of the believable and pressing against the perimeter of the possible. This characterisation of design as a means of 'cultural research' closely parallels the aspirations of Critical Design. Indeed Lukic [4] views design as a way to probe the emotional space between the human and the artefact and, in a wider sense, a more complete understanding of our object world will provide a means through which we can better understand ourselves. We live in a world where everything seems possible and as a consequence have lost the sense of wonder. Maybe Critical Design is an initial step towards regaining that wonder and better understanding our own condition.

\section{References}

1. Dorst, K.: Design problems and design paradoxes. Design Issues 22(3), 4-17 (2006)

2. Dunne, A.: Hertzian Tales - Electronic Products, Aesthetic Experience and Critical Design. RCA/CRD Research Publications, Royal College of Art, London (1999)

3. Bleecker, J., Nova, N.: A synchronicity: Design Fictions for Asynchronous Urban Computing, The Architectural League of New York (2009),

http: / / www.situatedtechnologies.net

4. Lukic, B.: NonObject. MIT Press, Cambridge (2011) 